OPEN ACCESS

Edited by:

Caroline Isaksson,

Lund University, Sweden

Reviewed by:

Adam Michael Fudickar, Indiana University Bloomington,

United States

Marta Szulkin

University of Warsaw, Poland

*Correspondence:

Pablo Capilla-Lasheras

p.capilla@exeter.ac.uk

Specialty section:

This article was submitted to Behavioral and Evolutionary Ecology,

a section of the journal

Frontiers in Ecology and Evolution

Received: 25 February 2017 Accepted: 31 May 2017

Published: 16 June 2017

Citation:

Capilla-Lasheras P, Dominoni DM Babayan SA, O'Shaughnessy PJ, Mladenova M, Woodford $L$

Pollock CJ, Barr T, Baldini F and Helm B (2017) Elevated Immune Gene

Expression Is Associated with Poor Reproductive Success of Urban Blue

Tits. Front. Ecol. Evol. 5:64.

doi: 10.3389/fevo.2017.00064

\section{Elevated Immune Gene Expression Is Associated with Poor Reproductive Success of Urban Blue Tits}

\author{
Pablo Capilla-Lasheras ${ }^{1,2 *}$, Davide M. Dominoni ${ }^{2,3}$, Simon A. Babayan ${ }^{2}$, \\ Peter J. O'Shaughnessy ${ }^{2}$, Magdalena Mladenova ${ }^{2}$, Luke Woodford ${ }^{2}$, \\ Christopher J. Pollock ${ }^{2}$, Tom Barr ${ }^{4}$, Francesco Baldini ${ }^{2}$ and Barbara Helm ${ }^{2}$ \\ ${ }^{1}$ Centre for Ecology and Conservation, College of Life and Environmental Sciences, University of Exeter, Penryn, United \\ Kingdom, ${ }^{2}$ Institute of Biodiversity, Animal Health and Comparative Medicine, University of Glasgow, Glasgow, United \\ Kingdom, ${ }^{3}$ Department of Animal Ecology, Netherlands Institute of Ecology, Wageningen, Netherlands, ${ }^{4}$ Institute of Infection, \\ Immunity and Inflammation, University of Glasgow, Glasgow, United Kingdom
}

Urban and forest habitats differ in many aspects that can lead to modifications of the immune system of wild animals. Altered parasite communities, pollution, and artificial light at night in cities have been associated with exacerbated inflammatory responses, with possibly negative fitness consequences, but few data are available from free-living animals. Here, we investigate how urbanization affects major immune pathways and experimentally test potentially contributing factors in blue tits (Cyanistes caeruleus) from an urban and forest site. We first compared breeding adults by quantifying the mRNA transcript levels of proteins associated with anti-bacterial, anti-malarial (TLR4, LY86) and anti-helminthic (Type 2 transcription factor GATA3) immune responses. Adult urban and forest blue tits differed in gene expression, with significantly increased TLR4 and GATA3, but not $\angle Y 86$, in the city. We then experimentally tested whether these differences were environmentally induced by cross-fostering eggs between the sites and measuring mRNA transcripts in nestlings. The populations differed in reduced reproductive success, with a lower fledging success and lower fledgling weight recorded the urban site. This mirrors the findings of our twin study reporting that the urban site was severely resource limited when compared to the forest. Because of low urban survival, robust gene expression data were only obtained from nestlings reared in the forest. Transcript levels in these nestlings showed no (TLR4, LY86), or weak (GATA3), differences according to their origin from forest or city nests, suggesting little genetic or maternal contribution to nestling immune transcript levels. Lastly, to investigate differences in parasite pressure between urban and forest sites, we measured the prevalence of malaria in adult and nestling blood. Prevalence was invariably high across environments and not associated with the transcript levels of the studied immune genes. Our results support the hypothesis that inflammatory pathways are activated in an urban environment and suggest that these differences are most likely induced by environmental factors.

Keywords: urban ecology, inflammation, immunity, gene expression, blue tits, TLR4, LY86, GATA3 


\section{INTRODUCTION}

Urban areas are the fastest growing land cover globally and are projected to increase a further $30 \%$ by 2030 (Seto et al., 2012). The modification of the natural landscape caused by urbanization poses novel challenges to wildlife. For example, urbanization is associated with altered food webs, parasite communities, and chemical, light and noise pollution (Grimm et al., 2008; Alberti, 2015; Isaksson, 2015). To thrive in these novel environments requires changes in behavior and physiology at the phenological and, possibly, genetic level. Such changes have, indeed, been found in urban populations of several species, indicating that they accommodate some of the challenges of city life (Isaksson, 2010; Munshi-South and Kharchenko, 2010; Dominoni et al., 2013a, 2016; Nemeth et al., 2013; Atwell et al., 2014; Gil et al., 2014; Giraudeau et al., 2014; Davies et al., 2016; Watson et al., 2017). Nonetheless, urban environments are linked to reductions in fitness and health in a substantial number of organisms (Chamberlain et al., 2009; Murray et al., 2015). Hence, urban habitats are sometimes considered ecological traps which attract organisms, for example by anthropogenic food availability, but are insufficient for supporting successful rearing of offspring (Plummer et al., 2013; Sumasgutner et al., 2014; Lamb et al., 2017). There is a need, therefore, to understand the mechanisms by which urbanization reduces reproductive success.

Despite their relevance for understanding urban adaptation, the proximate physiological mechanisms that underpin differences in behavior, life histories and fitness between urban and rural populations of wild animals still remain largely elusive (but see Dominoni et al., 2013b; Atwell et al., 2014; Davies et al., 2016; Salmón et al., 2016). Whereas some physiological responses in urban animals have been investigated thoroughly, such as reproductive (Schoech et al., 2004; Partecke et al., 2006; Dominoni et al., 2013b) and stress physiology (Bonier, 2012), others have received little attention. Recently, a study using transcriptome analysis (RNA-seq) has broadly examined the ways physiological systems differ between an urban and rural population of a songbird, the great tit (Parus major) (Watson et al., 2017). Among the systems highlighted in this study, immunity showed particularly clear differences, corroborating reports of substantially reduced health of urban populations in several species (Martin et al., 2010; Isaksson, 2015; Murray et al., 2015). Given the central role of the immune system for determining fitness and given its sensitivity to environmental factors, differences in immunity are thus strong candidates for linking urbanization to reduced reproductive success (Martin et al., 2010; Isaksson, 2015; Watson et al., 2017).

Urban environments can affect the immune system by modulating the structure of the parasite community to which animals are exposed and potentially respond to. Cities have been associated with altered parasite communities and altered infection dynamics (Fokidis et al., 2008; Evans et al., 2009; Giraudeau et al., 2014; Neiderud, 2015). For example, foraging behavior in cities is thought to enhance the prevalence of intestinal coccidians (Giraudeau et al., 2014), potentially driven by increasing contact rates at feeders (Becker et al., 2015). Several other factors associated with urban environments can affect the activation of particular immune pathways of wild animals. Prevalent urban conditions, such as chemical pollution and artificial light at night, can act as environmental stressors influencing the immune system and promoting proinflammatory immune profiles (Halliwell and Gutteridge, 2002; Bedrosian et al., 2011; Fonken et al., 2013; Isaksson, 2015; Watson et al., 2017). Low-quality and changed diet in urban areas can also enhance pro-inflammatory immune processes, which in turn can impose behavioral and physiological costs on animals (McGraw et al., 2006; Andersson et al., 2015; Becker et al., 2015; Isaksson, 2015). Furthermore, nutritional stress and resource restriction can exacerbate trade-offs between different biological processes, for example through resource allocation to growth vs. immunity (Sheldon and Verhulst, 1996; Norris and Evans, 2000). The findings of the transcriptomics study by Watson et al. (2017) showed that in an urban songbird population, where some of the above factors are effective, inflammatory immune genes were indeed upregulated. Experimental studies that measure candidate genes are now needed to clarify the origin of such differences, and links to fitness need to be established.

Here we examined how urban life affects avian immunity and fitness traits. As a study species, we used another parid songbird that is common in city and forest environments, the blue tit (Cyanistes caeruleus). Blue tits reportedly show reduced reproductive investment (e.g., clutch size and egg size) and reduced reproductive success in urban compared to rural populations (Chamberlain et al., 2009; Bailly et al., 2016b). We experimentally studied blue tits at two sites, one in an urban park area in Glasgow (UK), and one in a National Park $40 \mathrm{~km}$ away. The same populations were simultaneously investigated in a twin study on food resource availability, food provisioning and stable isotope signatures in eggs and blood samples (Pollock et al., 2017). This parallel study design allowed us to link, for the same sites, comparisons of immunity with resource restriction. We first tested the hypothesis that adult urban blue tits show increased expression of genes associated with inflammation compared to blue tits from a forest habitat. Specifically, using RT-qPCR, we measured the transcript levels of TLR4 and LY86, which are involved in anti-bacterial and anti-malarial responses (Medzhitov, 2001). We also tested the type 2 transcription factor GATA3, which is central to innate and adaptive immunity against parasitic helminths and immune homeostasis (Wang et al., 2011; Tindemans et al., 2014) and showed elevated gene expression in urban great tits (Watson et al., 2017).

We then investigated whether any urban-forest differences in immune gene transcript levels are already present during the nestling stage. Urban-forest immune differences in nestlings could arise either through environmental effects during early life, genetic or maternal effects. Thus, we cross-fostered eggs between and within the urban and forest sites to distinguish whether any difference in immune activation of nestlings was induced by the environment or controlled by genetic or maternal mechanisms (Watson et al., 2017). Finally, from the crossfostering experiment, we quantified the reproductive success at the two sites and, thus, investigated possible associations between environment, immunity and reproductive success. We also examined prevalence of a common avian disease, avian 
malaria, as a potential driver of differences in expression of our immune markers (Martin et al., 2014; Videvall et al., 2015).

Increased levels of TLR4 and LY86 in adult urban birds are predicted on the basis of the hypothesis that the urban environment enhances inflammation. We also predicted increased levels of GATA3 in adult urban birds as a consequence of high activation of immune pathways against intestinal parasites, whose transmission is thought to be exacerbated by anthropogenic food provisioning at bird feeders (Becker et al., 2015). Expression of these three genes was also reported to be increased in at least one tissue in the transcriptome study on great tits (Watson et al., 2017). For nestlings blue tits, we predicted that urban-raised offspring might also show heightened expression of immune genes, indicating a direct effect of the environment on their immune profiles within their short postnatal life-span. We further predicted that cross-fostered nestlings should also differ in their immune gene expression profiles by origin, either due to micro-evolutionary change or based on differences in maternal investment. Assuming that higher expression levels in immune genes were selected for in urban birds, we expected higher expression levels in nestlings originating from eggs laid the urban environment regardless of their rearing environment. We also expected lower reproductive investment, fledging success and fledgling body mass in blue tits from the urban compared to the forest environment. The differences in reproductive success of urban and forest nests were indeed striking: $88 \%$ fledgling success in the forest compared to only $30 \%$ in the city. Consequently, in the cross-fostering experiment we obtained robust sample sizes on gene expression only for nestlings reared in the forest. We acknowledge limitations of our study arising from low sample sizes and from a design that involves only two sites (one urban and one rural) in a single year. Our experimental approach, using cross-fostering, addresses some of these concerns by effectively providing within-site replication. However, urban ecology will require studies in multiple sites and years, and on a broad range of organisms, before major, generalizable advances can be achieved (Watson et al., 2017).

\section{MATERIALS AND METHODS}

\section{Experimental Design and Field Protocol}

Field work was carried out in one urban and one forest location in Scotland in May and June of 2014. In both sites, existing nest-box study systems were used (woodcrete boxes: $260 \times 170 \times 180 \mathrm{~mm}$, $\varnothing=32 \mathrm{~mm}$, Schwegler, Germany). The urban site was located

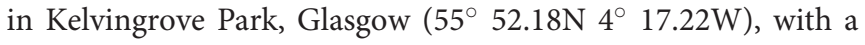
total of 60 bird nest-boxes. The forest location was situated in oak woodland near the Scottish Centre for Ecology and the Natural Environment (SCENE; $56^{\circ} 7.73 \mathrm{~N} 4^{\circ} 36.79 \mathrm{~W}$ ), with a total of 143 bird nest-boxes. Twenty clutches of blue tits in the city and 22 in the forest were manipulated prior to clutch completion: 10 nests in the city and 12 in the forest were swapped within locations, representing control nests; and 10 nests were swapped across locations, representing experimentally cross-fostered nests (in total, 42 manipulated nests). Clutches within and across locations were matched based on sixth-egg laying date. Before swapping clutches, every egg involved in the experiment was individually marked, weighed ( \pm 0.01 grams) and kept at $4^{\circ} \mathrm{C}$ overnight. Clutch size was reduced to six viable eggs at both sites in order to control for possible inter-habitat differences in clutch size. After females laid the sixth egg, clutches were swapped as explained above. When more than six eggs were present in a nest on the day of swapping, the six experimental eggs were randomly chosen. After swapping clutches, nests were checked every other day and newly laid eggs were replaced by dummy eggs. Using dummy eggs, we always kept the original number of eggs laid by females (each nest contained six real eggs plus a variable number of dummy eggs depending on the number of eggs that females actually laid). Dummy eggs were removed from nests after real eggs hatched. The total number of eggs laid by each female was recorded and termed "natural clutch size."

After the 10th day of incubation, nests were monitored daily and hatch date was precisely assigned for every nest. On day 13 after first-egg hatching, blue tit nestlings were weighed $( \pm 0.05$ grams), ringed with a unique metal ring and between 20 and 75 $\mu \mathrm{L}$ of blood were collected from their brachial veins (stored in $250 \mu \mathrm{L}$ of RNAlater ${ }^{\circledR}$ for gene expression analysis). Additionally, between 20 and $75 \mu \mathrm{L}$ of whole blood were stored in $>99 \%$ ethanol for molecular screening of malaria parasites. Between 10 and 12 days post-hatching, we aimed to capture one or two of the respective parents while provisioning and to sample adults as described for chicks. However, when we realized the low overall breeding success in our urban population we greatly reduced efforts of catching parents to avoid additional risks to the broods. In total, we obtained samples of 24 adult birds (Table 1). Nestboxes were checked 16-20 days after expected fledging dates in search of dead nestlings. Since clutch size was reduced to six eggs, hatching success was defined as number of hatchlings divided by six. Number of fledglings over number of hatchlings represented fledging success. Table 1 summarizes sample sizes throughout different breeding stages between our urban and forest site, which became progressively disparate because of high chick mortality in the city.

\section{Ethics Statement}

All bird sampling was conducted following the directions and legislations of UK Home Office (project license: 70/7899 to BH, and personal licenses to DD and $\mathrm{BH}$ ), Scottish Natural Heritage (52463 to BH) and British Trust for Ornithology (Scientific C and $\mathrm{T}$ licenses to $\mathrm{BH}$ and $\mathrm{DD}$, respectively).

\section{Expression of Immune and Reference Genes}

\section{Primer Design}

Blue tit sequences of TLR4 (toll-like receptor 4), LY86 (lymphocyte antigen 86, also known as MD1), GATA3 (GATA Binding Protein 3) and of the candidate reference genes, HPRT (Hypoxanthine-guanine phosphoribosyl transferase), PMM1 (Phosphomannomutase 1), SDHA (succinate dehydrogenase complex, subunit A) and TFRC (transferrin receptor protein 1) (Olias et al., 2014) were obtained from the blue tit genome (Mueller et al., 2016). Gene sequences were compared in BLAST against the zebra finch (Taeniopygia guttata) genome (Warren et al., 2010) in order to design primers on the 
TABLE 1 | Summary of sample sizes that entered the analysis: number of clutches, nestlings and adults of each experimental group at every breeding stage for our two study sites.

\begin{tabular}{|c|c|c|c|c|}
\hline \multicolumn{5}{|c|}{ Initial number of nests } \\
\hline & & Urban & Forest & Total \\
\hline \multicolumn{2}{|c|}{ Cross-fostered group } & 10 & 10 & 20 \\
\hline \multicolumn{2}{|c|}{ Control group } & 10 & 12 & 22 \\
\hline \multicolumn{2}{|l|}{ Total } & 20 & 22 & 42 \\
\hline \multicolumn{5}{|c|}{ Number of clutches successfully hatched ${ }^{a}$} \\
\hline \multicolumn{2}{|c|}{ Cross-fostered group } & 7 & 6 & 13 \\
\hline \multicolumn{2}{|c|}{ Control group } & 8 & 9 & 17 \\
\hline \multicolumn{2}{|l|}{ Total } & 15 & 15 & 30 \\
\hline \multicolumn{5}{|c|}{ Number of hatchlings ${ }^{b}$} \\
\hline \multicolumn{2}{|c|}{ Cross-fostered group } & 32 & 25 & 57 \\
\hline \multicolumn{2}{|c|}{ Control group } & 30 & 39 & 69 \\
\hline \multicolumn{2}{|l|}{ Total } & 62 & 64 & 126 \\
\hline \multicolumn{5}{|c|}{ Number of fledglings } \\
\hline \multicolumn{2}{|c|}{ Cross-fostered group } & 9 & 20 & 29 \\
\hline \multicolumn{2}{|c|}{ Control group } & 9 & 36 & 45 \\
\hline \multicolumn{2}{|c|}{ Total } & 18 & 56 & 74 \\
\hline \multicolumn{5}{|c|}{ Number of individuals sampled for RT-qPCR analysis ${ }^{c}$} \\
\hline \multirow[t]{3}{*}{ Nestlings } & Cross-fostered group & 4 & 16 & 20 \\
\hline & Control group & 4 & 24 & 29 \\
\hline & Total & 8 & 40 & 48 \\
\hline \multicolumn{2}{|l|}{ Adults } & 13 & 11 & 24 \\
\hline
\end{tabular}

Cross-fostered clutches were swapped between sites, control clutches were swapped within sites.

${ }^{a}$ Clutches with at least one egg hatched. ${ }^{b}$ Maximum number of hatchlings per clutches was six since every clutch was experimentally reduced to six eggs. ${ }^{C}$ With successful gene expression data for both reference genes used in data normalization.

correct gene regions. Primers were designed using Primer Express $^{\mathrm{TM}}$ 2.0.0 (Applied Biosystems) as described previously (O’Shaughnessy et al., 2008). In order to avoid genomic DNA (gDNA) amplification, every primer pair was designed to flank an intron of more than 1,000 base pairs whenever possible. All primer sequences (Table S1), as well as the validation of reference genes (Figure S1), are detailed as Supplementary Material.

\section{RNA Extraction, Reverse Transcription and RT-qPCR Protocol}

Blood samples stored in RNAlater ${ }^{\circledR}$ were centrifuged for 5 min at 5,000 RPM, and RNA in the cell fraction isolated using TRIzol ${ }^{\circledR}$ reagent (Life Technologies, Thermo Fisher Scientific 2015). Extracted RNA was reverse transcribed using random hexamers and Moloney murine leukemia virus reverse transcriptase (Superscript III, Invitrogen Ltd.) (for detailed protocols see O'Shaughnessy and Murphy, 1993; O'Shaughnessy et al., 1994). Levels of mRNA were measured by real-time quantitative PCR using the SYBR Green method (O'Shaughnessy and Murphy, 1993; O’Shaughnessy et al., 1994). The efficiency of the seven employed primer pairs was between 91 and 120\% in all the cases. None of the primer pairs amplified gDNA. One unique gene was run in each RT-qPCR 96-well plate along with a non-template control (NTC). Every sample was always run in duplicate and only samples with similar duplicate results were considered for final analysis. The vast majority of samples included in analyses had $\mathrm{C}_{\mathrm{t}}$ differences between replicates below one. Five samples showed $\mathrm{C}_{t}$ differences between one and two, and two additional samples in the final analysis had replicate $\mathrm{C}_{\mathrm{t}}$ differences larger than two (2.07 and 2.18). The exclusion of the samples with $C_{t}$ differences above 2 or the samples with $\mathrm{C}_{t}$ differences above 1 did not change the results. For details of RT-qPCR data normalization, see Supplementary Material.

\section{Screening of Malaria Parasites}

Avian malaria collectively refers to blood parasites of the three taxa Leucocytozoon, Haemoproteus and/or Plasmodium [PMID:15357072]. We tested for the presence or absence of any of these parasites using a nested PCR approach which identified Leucocytozoon in one reaction, and either of Haemoproteus and Plasmodium in another reaction (Hellgren et al., 2004). In short, DNA from blood samples stored in >99\%-ethanol was extracted using a commercial kit (DNeasy whole-blood extraction kit, Qiagen). Eluted DNA was amplified by 20 cycles at $94^{\circ} \mathrm{C}$ for $30 \mathrm{~s}, 50^{\circ} \mathrm{C}$ for $30 \mathrm{~s}$ and $72^{\circ} \mathrm{C}$ for $45 \mathrm{~s}$. A 2 $\mu \mathrm{l}$-aliquot from the result of this reaction was further amplified for 35 cycles at $94^{\circ} \mathrm{C}$ for $30 \mathrm{~s}, 54^{\circ} \mathrm{C}$ for $30 \mathrm{~s}$, and $72^{\circ} \mathrm{C}$ for 45 s. Both PCRs were performed in $20-\mu l$ reaction mixture using $10 \mu \mathrm{l}$ of GoTaq $^{\circledR}$ universal PCR master mix (Promega) and $0.6 \mu \mathrm{M}$ of each primer. Products of the second PCR reaction were examined on a $1 \%$ agarose gel. The presence of Leucocytozoon and/or Haemoproteus/Plasmodium parasites was further checked by sequencing 24 PCR positive bands (12 for Leucocytozoon and 12 for Haemoproteus/Plasmodium, corresponding to samples positive for both taxa) (Eurofins Genomics). In all the positive samples that we tested, sequencing confirmed the presence of at least one avian malaria parasite, Leucocytozoon (GenBank Accession Numbers KY981756KY981765) and/or Haemoproteus (GenBank Accession Numbers KY981753-KY981755). No Plasmodium was detected. In nine out of 12 samples that were positive for both Leucocytozoon and Haemoproteus by PCR, sequencing revealed that only one of the two parasites was actually present, suggesting that the observed double infections might not always be true but possibly an artifact of the PCR procedure due to cross-reaction of the primers.

\section{Statistical Analysis} Model Selection Approach

For every modeled response variable, data analysis started with a global model including every biologically important predictor (see below). Then, model selection based on Akaike's Information Criterion (AIC, Burnham and Anderson, 2002; Burnham, 2004; Burnham et al., 2011) was applied to investigate alternative hypotheses on the effects of urban-forests conditions and of our experimental manipulation on immune gene expression, 
breeding investment and breeding success. Models were ranked based on their AICc and considered similarly supported if their $\triangle \mathrm{AICc}$ value was $<2$. Poisson and binomial models were checked for over-dispersion by comparing residual deviance and residual degrees of freedom. Linear models and linear mixed model residuals were inspected to check that they met the assumption of normality, and collinearity between pairs of explanatory variables was checked before accepting the results of any statistical model. Data analysis was carried out in R 3.3.2 (R Core Team, 2016) using the lme4 (Bates et al., 2014) and MuMin (Barton, 2016) packages.

\section{Immune Transcript Levels and Malaria Prevalence in Adult Blue Tits}

After RT-qPCR data normalization, adult levels of TLR4, LY86, and GATA3 were analyzed using linear models (LMs). Habitat (a factor with two levels: urban or forest) and adult body mass 10-12 days after hatching of their clutch were originally included as predictors in every model. Weight information was missed for two adult birds with successful gene expression data. Weight appeared to have little importance in explaining variation in gene expression and we, therefore, present statistical results for models containing weight in Table S2. In the main text, we report results for models without weight but include the two additional birds to increase our sample size and, hence, the confidence in our estimates of the effect of habitat. Malaria prevalence was compared across habitats using Fisher's exact test. Because little variation in infection status was observed in adult birds, we were unable to investigate its association with immune transcript levels.

\section{Immune Transcript Levels and Malaria Prevalence in Cross-Fostered Nestlings}

Originally, the main purpose of this analysis was to investigate the effect of the original and rearing environment on immune transcript levels. However, because of the high mortality in our urban environment (see Section Results), sample sizes from urban raised nestlings were very low. Hence, we focus our main analysis only on nestlings raised in the forest and present preliminary results for the full cross-fostering design as Supplementary Material.

Nestling TLR4, LY86, and GATA3 transcript levels were analyzed using linear-mixed models (LMMs). Original environment (a factor with two levels: urban or forest) and weight of chicks on day 13 were included as fixed effects. Malaria infection status (factor with two levels, YES/NO) was also included as a predictor. Nest ID was included as a random factor in every model as several nestlings were measured per nest.

\section{Reproductive Investment and Breeding Success of Urban and Forest Cross-Fostered Nests}

We compared several measures of reproductive investment and breeding success of adult females as follows. Female investment was quantified by number (i.e., natural clutch size) and size of eggs laid. Natural clutch size was modeled as a Poisson variable in a generalized linear model (GLM) including habitat, and clutch completion date (as a linear and a quadratic term) to account for temporal trends. We also included experimental group (cross-fostered or control) and its interaction with site to test whether our experimental design differed across habitats. Individual egg weight was modeled using LMMs including as explanatory variables original environment, experimental group, their interaction, natural clutch size and 1st egg laying date (as a linear and a quadratic term). Nest ID was always kept as random factor.

We then examined reproductive success of the urban and forest nests. Hatching and fledging success were analyzed with generalized linear mixed models (GLMMs) using binomial distributions with logit link functions. Due to over-dispersed model residuals, observation-level random factors were employed and yielded good model fit (Harrison, 2015). Original and rearing environment, their interaction, and clutch completion date-for hatching success-or hatch date (linear and quadratic terms)-for fledgling success-were included as explanatory variables. Weight of fledglings on day 13 after hatching was analyzed by a LMM, keeping Nest ID as a random factor and using original and rearing environment, their interaction, hatch date (linear and quadratic terms), brood size on day 13 , and the interaction between rearing environment and brood size as explanatory variables.

\section{RESULTS}

\section{Immune Transcript Levels and Malaria Prevalence of Urban and Forest Adults}

Adult urban blue tits showed higher levels of TLR4 and GATA3 than forest blue tits (Figure 1). Including habitat as a predictor generated models for these two immune genes that were superior in AICc than intercept-only models (Table 2). Removing a high-value outlier in GATA3 transcript levels of urban birds (Figure 1) did not qualitatively change the statistical outcome. After removal of this outlier, the model containing habitat as a predictor was still the most supported by the data, with a decrease in AICc of 2.4 compared to the intercept-only model. For LY86 expression, we did not find statistical evidence for an alteration across habitats (Table 2, Figure 1B). Body weight of adults 10-12 days after hatching of their clutch was not an important predictor for transcript levels of any immune gene (Table S2).

Every screened adult urban bird scored positive for malaria infection $(n=6)$. Out of 9 forest birds tested, 8 were positive for malaria parasites. These results indicated no association between malaria prevalence and habitat in adult blue tits (Fisher's exact test, $p>0.90$ ), suggesting that differential pressure of malaria parasites across environments does not underlay our results of immune gene expression.

\section{Immune Transcript Levels and Malaria Prevalence of Forest-Reared Nestlings}

Our data suggested no differences in transcript levels of TLR4 and LY86 in forest-reared nestlings due to habitat of origin, malaria parasite infection or weight 13 days after hatching (Figure 2). For the expression of these two genes, interceptonly models were most supported by the data (Table 3 ). The 


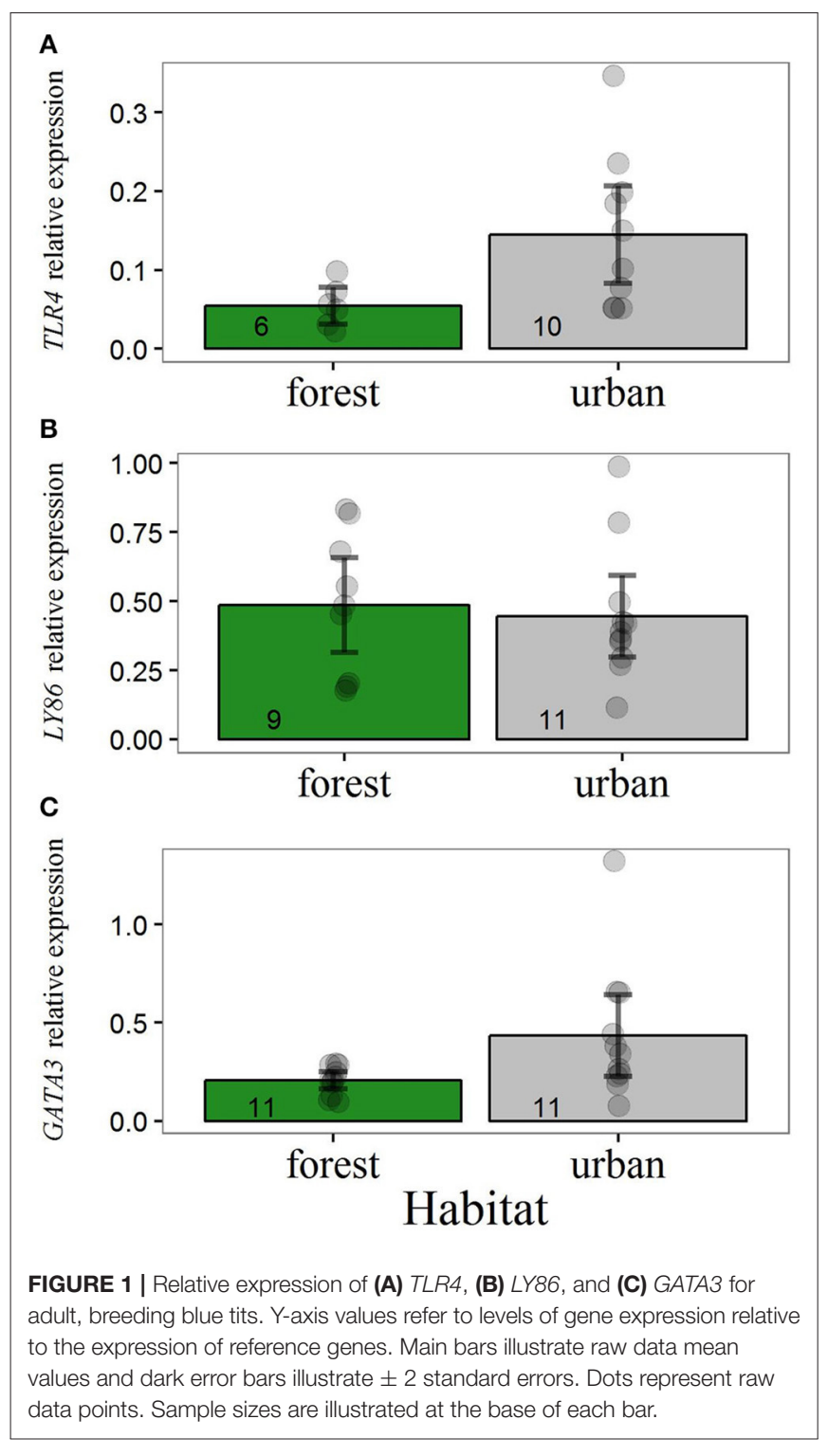

presence of malaria parasites did not predict TLR4 or LY86 levels. Malaria infection status was only kept in models with $\triangle \mathrm{AICc}$ values larger than 2. For GATA3, we found some evidence for an effect of the original environment on nestling transcript levels. Urban-originated nestlings reared in the forest had higher levels of GATA3 than forest-originated forest-reared birds (Figure 2C). Four competing models scored very similar AICc values, two of them containing original environment and weight on day 13 as predictors (Table 3). However, after removal of an urban-originated outlier with high GATA3 (Figure 2C), the effect of weight and of the original environment lost much importance and the intercept-only model became the most supported one (Table S3). Results for the full cross-fostering experiment, including urban-reared forest birds, are shown in Figure S2.

Prevalence of avian malaria in forest-reared nestlings was 79.16\% ( $n=48, S E=5.92 \%)$, whereas every screened urbanreared nestling was found positive $(n=4)$. Within forest-reared birds, malaria prevalence did not vary based on nestling origin (Fisher's exact test, $p=0.468, n=38$. Prevalence \pm standard error: forest-originated birds $=0.83 \pm 0.38$, urban-originated birds $=0.72 \pm 0.46)$.

\section{Breeding Success in Urban and Forest Cross-Fostered Nests}

Most metrics of breeding investment and success were lower in the urban compared to the forest site (Figure 3). Despite observed differences in clutch size between habitats (mean clutch size \pm SE: urban clutches $=7.70 \pm 0.34, n=20$; forest clutches $=8.63 \pm 0.48, n=22$ ), they did not received strong statistical support (Table 4). Urban-originated eggs were slightly lighter than forest-originated eggs and habitat of origin appeared in three out of four models with $\triangle \mathrm{AICc}<2$ for egg weight (the most supported one amongst them); however, the effect size was small, with urban eggs only $0.045 \mathrm{~g}$ lighter than forest ones. Experimental group was also kept in the set of top models showing that cross-fostered eggs were 0.05 grams heavier than control eggs (Figure 3A). No predictor was retained

TABLE 2 | Summarizing table of statistical models employed to explain variation in TLR4, LY86, and GATA3 transcript levels for adult blue tits.

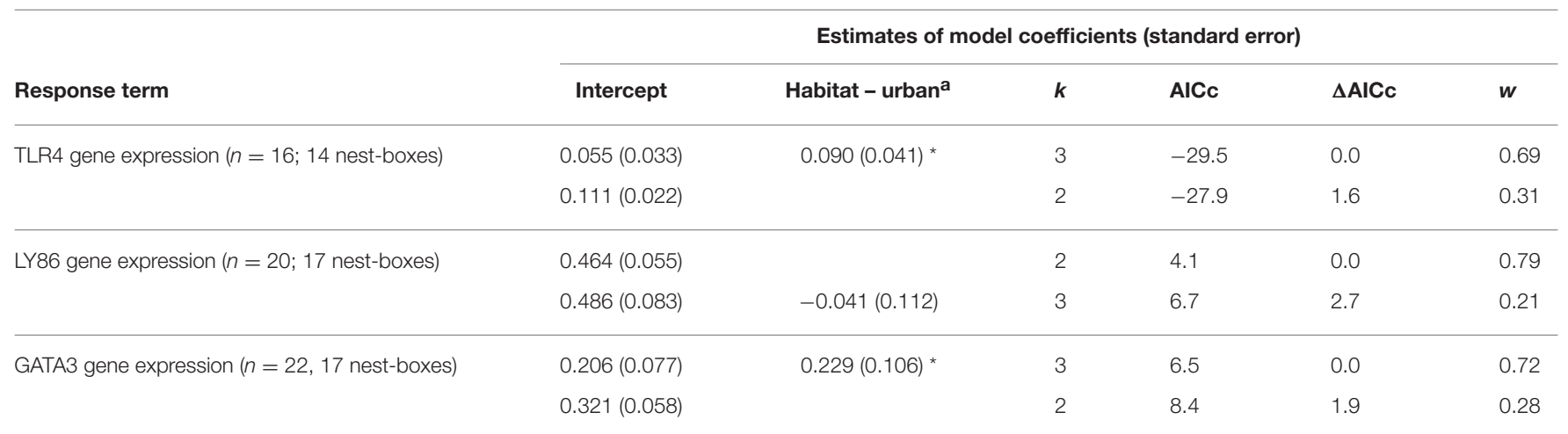

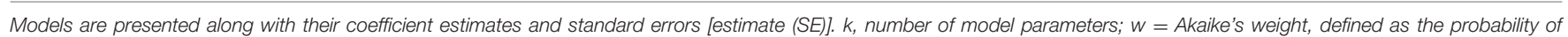

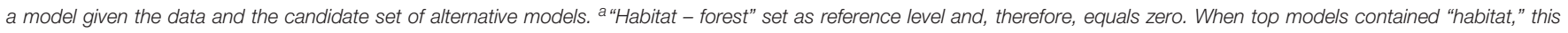
predictor was assessed by a likelihood-ratio test against the intercept-only model and *illustrates a p-value $<0.05$. See Table S2 for model estimates including adult weight. 


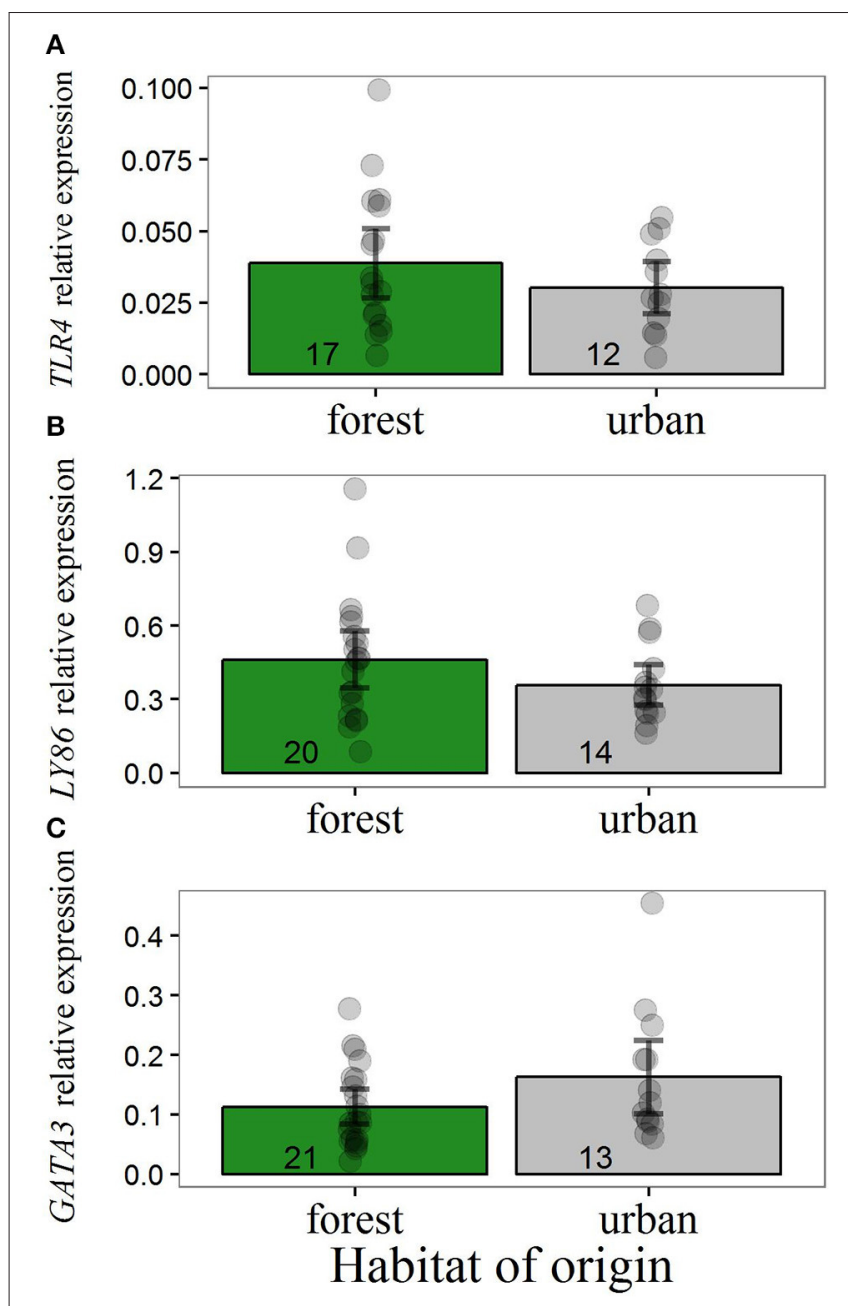

FIGURE 2 | Relative expression of (A) TLR4, (B) LY86, and (C) GATA3 for forest-reared nestlings hatched from cross-fostered eggs of the urban or forest site. $Y$-axis values refer to transcript levels relative to the expression of reference genes. Main bars illustrate raw data mean values and dark error bars illustrate \pm 2 standard errors. Dots represent raw data points. Sample sizes are illustrated at the base of each bar. Removal of the urban outlier in GATA3 analysis (C) led to qualitative and quantitative changes in the results regarding this gene (Table S3). Differences in sample size between Figure 2 and Table $\mathbf{1}$ are due to two nestlings with missing information for body weight. The inclusion of these additional data points does not change the results regarding the effect of the rearing habitat.

in the most supported model for hatching success (Table 5, Figure 3B) and habitat of origin only appeared in a model featuring a $\triangle \mathrm{AICc}$ value of 1.89 (ranked third in support). These results suggested no differences in hatching success due to habitat of origin or rearing habitat (Table 5). The urban rearing environment, however, had a very strong negative effect on fledging success as well as on nestling weight (Table 5). Regardless of their origin, forest-reared nestlings were on average 1.33 grams heavier and more than twice as likely to fledge as urban-reared birds (Figures 3C,D). Rearing habitat appeared in every model within the $\Delta 2$ set for fledging success and nestling weight (Table 5).

\section{DISCUSSION}

Reproductive success of blue tits was dramatically reduced in the city compared to the forest. Our study adds to existing evidence that urban environments commonly impair fitness and health in wild populations (Chamberlain et al., 2009; Murray et al., 2015; Bailly et al., 2016b). In most avian studies, fledging success and nestling weight were lower in urban than in more rural habitats (Chamberlain et al., 2009; Bailly et al., 2016b; Sprau et al., 2017). These findings are matched by observations in this study and in the parallel study of effects of food availability on other nests at our sites (Pollock et al., 2017). In addition to immediate effects of the environment on developing offspring, such differences could also reflect prenatal maternal investment (e.g., differences in egg composition, Toledo et al., 2016) or genetic differences between urban and rural populations (Mueller et al., 2013). Our cross-fostering experiment does not support these latter hypotheses as we found no strong effects of natal origin on reproductive and fitness traits (Figure 3). Slightly larger cross-fostered eggs from both sites were a spurious outcome of our alternating, experimental swaps. Overall, we provide experimental support for the existence of a significant negative postnatal effect of the urban environmental on breeding success in blue tits, although we acknowledge that further replication will be needed to consolidate these results.

These findings converge with a recent study on closely related great tits which also used a cross-fostering experiment and showed that negative implications of urban nesting (in this case, shortened telomeres) arose from the raising environment and not from genetic or maternal factors (Salmón et al., 2016); however, this study did not investigate the possible mechanistic causes of such differences. Our parallel study on food availability and provisioning behavior provided clear evidence of resource limitation and nutritional stress in our urban site compared to our forest location (Pollock et al., 2017). Whereas nestlings in the forest received predominantly caterpillars, the proportion of this preferred, high-quality diet was substantially lower for nestlings in the city. Pollock's data further suggest that parents partly resorted to other food, possibly including anthropogenic sources, to feed their nestlings and presumably themselves (Pollock et al., 2017). Shifts in diet, which were also reported for urban populations in other species (e.g., Murray et al., 2015), can have important effects on the nutritional state of urban animals, and consequently, also on their health (Andersson et al., 2015). Thus, the findings that we present here on immunity have to be interpreted against the backdrop of resource restriction in the urban site.

Our results from adult blue tits on transcript levels of immune genes support some of our initial hypotheses. Urban blue tits showed increased transcript levels of TLR4, a marker of inflammatory processes, although these findings were not paralleled for $L Y 86$. Several factors have been proposed to explain how the immune system of urban organisms is expected to change in response to the environment (Isaksson, 2015). Malaria parasite infection has been shown to affect the expression of TLR4 (Martin et al., 2014) and also LY86 in passerines birds (Videvall et al., 2015). In our study, malaria infection status 
TABLE 3 | Summarizing table of statistical models employed to explain variation in TLR4, LY86, and GATA3 transcript levels for forest-reared nestlings.

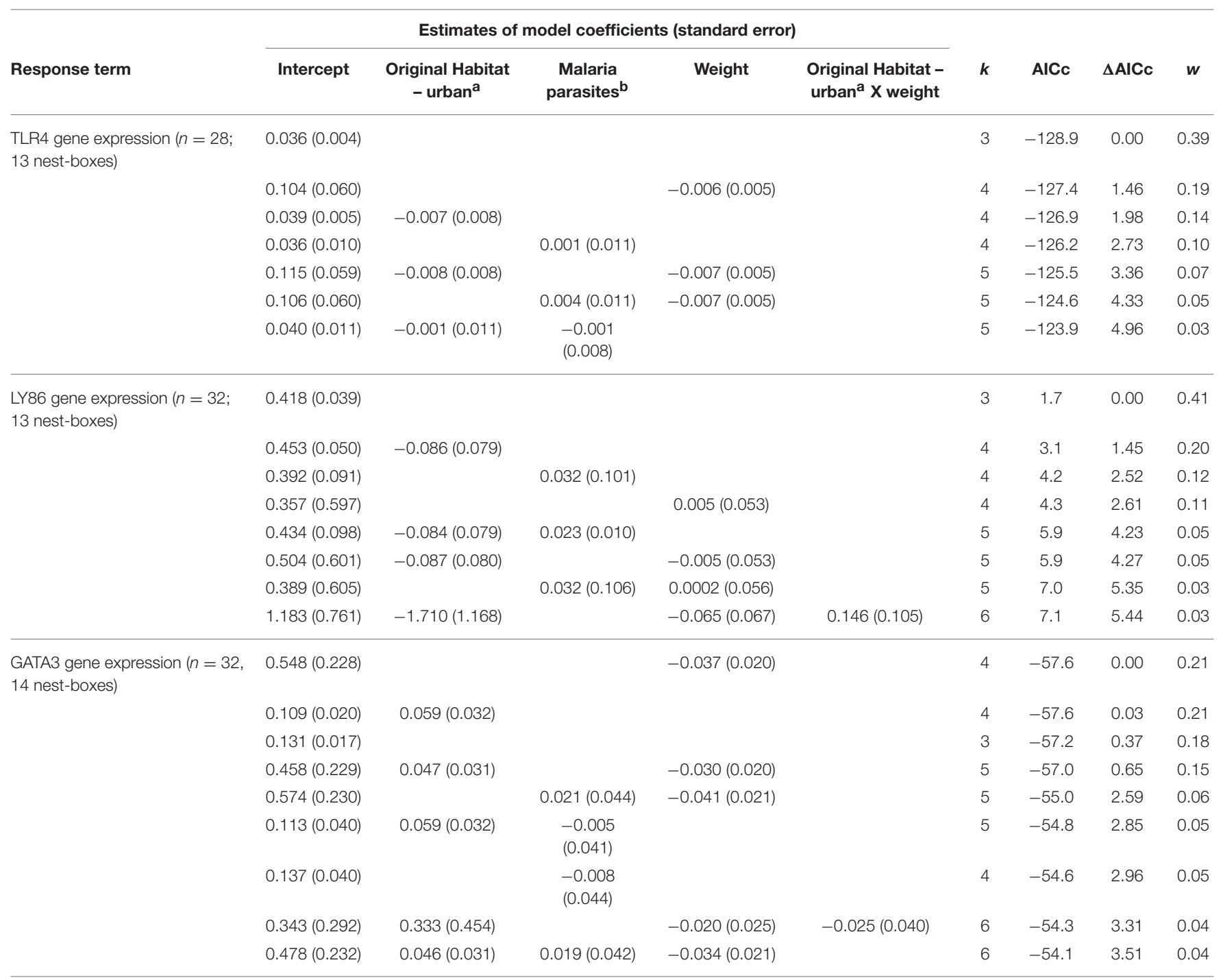

Models within a $\Delta / C c$ value of six are presented along with their coefficient estimates and standard errors [estimate (SE)]. $k=$ number of model parameters; $w=$ Akaike's weight, defined as the probability of a model given the data and the candidate set of alternative models. "O "Original habitat - forest" set as reference level and, thus, equals zero. ${ }^{b}$ Malaria parasite = "NO" fixed as reference level; therefore, the given coefficients represent the change in gene transcript levels associated with the presence of malaria parasites. The statistical importance of weight and habitat in the top two models for GATA3 was further assessed by a likelihood-ratio test comparing such models against the intercept-only one. In both cases, these tests yielded a $p$-value of 0.08 .

probably had little importance for TLR4 and LY86 levels across habitats. In contrast to other studies (Evans et al., 2009), malaria prevalence was consistently high at both of our sites; however, our statistical power was small and the lack of differences across habitat needs to be considered cautiously. Other intracellular pathogens found to vary in prevalence between urban and rural sites (Giraudeau et al., 2014) or in association with anthropogenic food provisioning (Becker et al., 2015), may also be important determinants of TLR4 and LY86 levels. Because we lack information on the wider pathogen assembly in our study sites, we cannot discard differences in other inflammatory pathogens as a cause of the observed gene expression patterns. Additional environmental factors could also explain differences in immunity between urban and forest populations. Low-quality and restricted diets are known to promote pro-inflammatory immune processes (Blount et al., 2003; McGraw et al., 2006; Isaksson, 2015; Nettle et al., 2017). Given our parallel findings of significant diet differences between our study populations (Pollock et al., 2017), it is likely that resource limitation has contributed to elevated inflammation in the city (Larsson et al., 2004; Isaksson, 2015). Costs of inflammation under resource limitation could have contributed to the birds' low reproductive success via exacerbated physiological trade-offs.

In contrast to TLR4, transcript levels of LY86 in adult blue tits did not match our predictions. Because TLR4 and LY86 interact (Lee et al., 2012), we expected to find a correlated pattern of expression between their gene expression. However, the interaction between these molecules is complex and can vary 


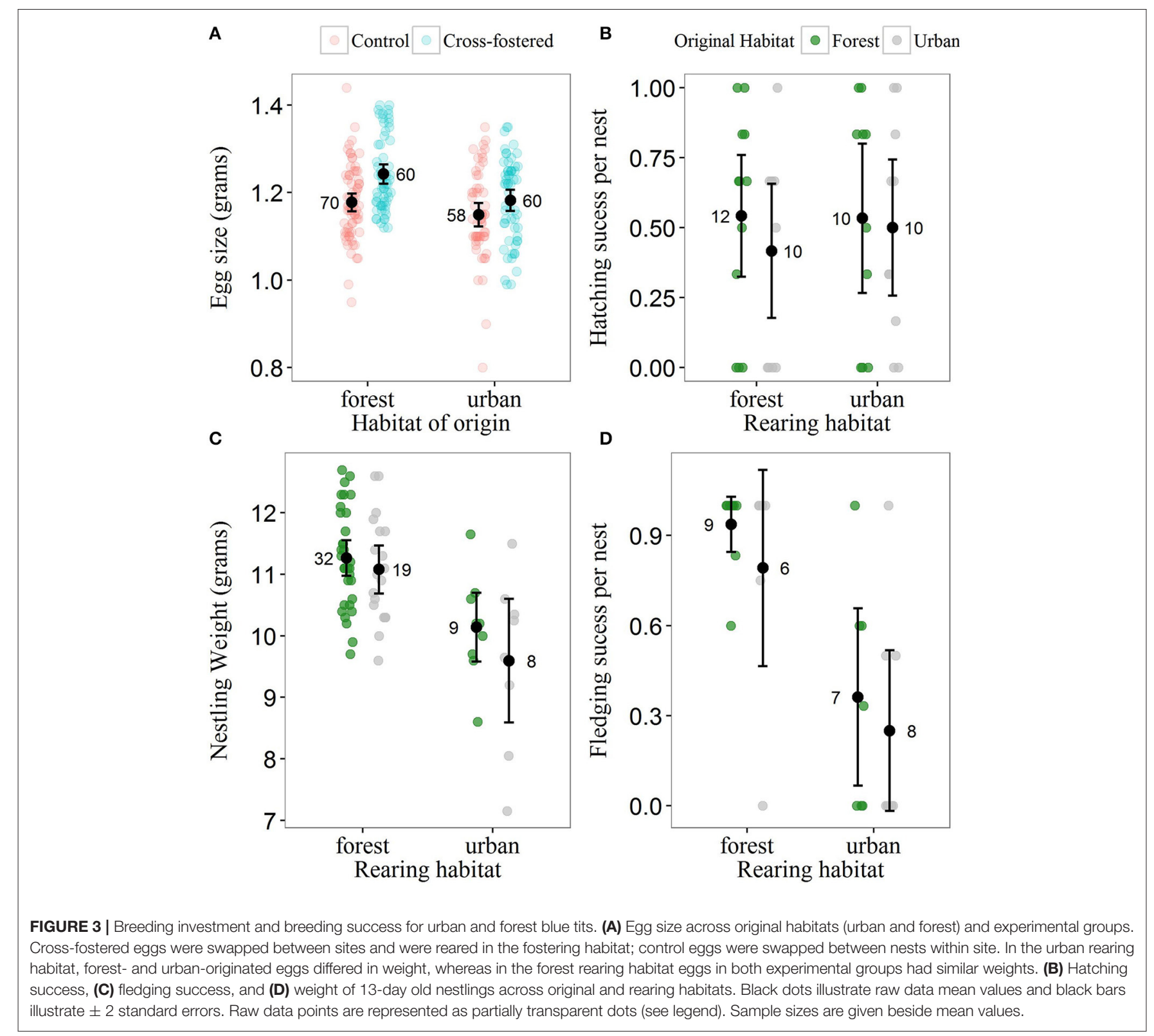

between cell types (Divanovic et al., 2005). The lack of differences in LY86 across habitats, in contrast to our findings regarding $T L R 4$, indicates that these two genes might respond differentially to the urban environment. TLR 4 expression may be particularly sensitive to urban-related environmental stressors. As well as acting as a receptor for pathogens (gram negative bacteria molecular patterns), TLR4 is implicated in the recognition of damage-associated molecular patterns that follow tissue damage or cellular apoptosis (Liu et al., 2014). Conceivably, TLR4 could have been additionally enhanced by urban-associated environmental factors that promote oxidative stress and tissue damage, for example, air pollution and artificial light at night (Isaksson, 2010; Fonken et al., 2013). Our findings on TLR4 and LY86 transcript levels can be compared to recent findings of the transcriptomic comparison between urban and rural populations of another parid, the great tit (Watson et al., 2017). In fully grown great tits, expression of TLR4 (gene ID ENSTGUG00000003342) tended to be elevated in blood and liver also in the city compared to the forest (Watson et al., 2017, Supplementary Datasets 1 and 2). Expression of LY86 (gene ID ENSTGUG00000002305) also tended to be higher in liver of urban great tits, but not in blood. Largely, therefore, patterns were similar in the two parid species.

The findings of higher GATA3 transcript levels in adult urban compared to forest blue tits also followed our initial predictions. The type 2 transcription factor GATA3 constitutes a major regulatory component of the immunity against helminth parasites (Tindemans et al., 2014). Although we were unable 
TABLE 4 | Summarizing table of statistical models employed to explain variation in natural clutch size and egg weight (in g).

\begin{tabular}{|c|c|c|c|c|c|c|c|c|c|c|}
\hline $\begin{array}{l}\text { Response } \\
\text { term }\end{array}$ & \multicolumn{6}{|c|}{ Estimates of model coefficients (standard error) } & $k$ & AlCc & $\Delta \mathrm{AICc}$ & $w$ \\
\hline \multirow{2}{*}{$\begin{array}{l}\text { Clutch size } \\
(n=42)\end{array}$} & $2.103(0.054)$ & & & & & Not included & 1 & 186.0 & 0 & 0.29 \\
\hline & $2.156(0.073)$ & $-0.115(0.108)$ & & & & Not included & 2 & 187.1 & 1.08 & 0.17 \\
\hline \multirow{4}{*}{$\begin{array}{l}\text { Egg weight } \\
(n=248)\end{array}$} & $1.185(0.020)$ & $-0.045(0.024)$ & $0.050(0.024)^{\star}$ & & & & 5 & -632.3 & 0 & 0.17 \\
\hline & $1.164(0.017)$ & & $0.048(0.025)$ & & & & 4 & -631.0 & 1.33 & 0.09 \\
\hline & $1.151(0.054)$ & $-0.043(0.024)$ & $0.048(0.024)$ & & & $0.004(0.006)$ & 6 & -630.7 & 1.66 & 0.07 \\
\hline & $1.178(0.022)$ & $-0.031(0.033)$ & $0.064(0.033)$ & & $-0.029(0.047)$ & & 6 & -630.6 & 1.73 & 0.07 \\
\hline
\end{tabular}

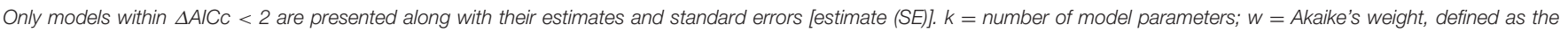

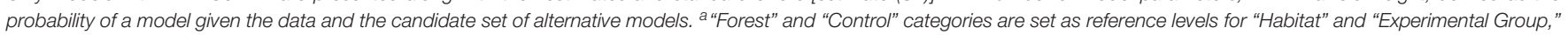

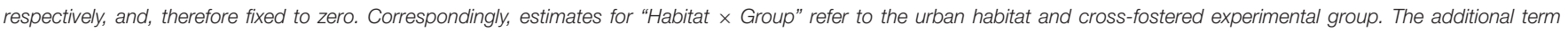

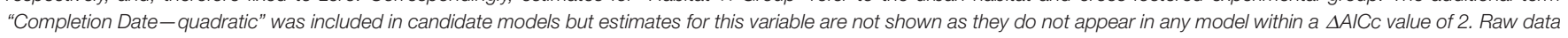

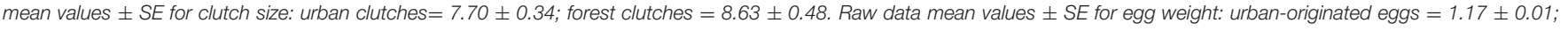

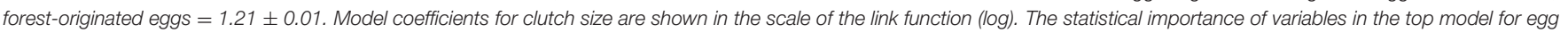
weight was further assessed by a likelihood-ratio test, dropping one predictor at a time, and *illustrates p-values $<0.05$.

TABLE 5 | Summarizing table of statistical models employed to explain variation in hatching success, fledging success and nestling weight (in g).

\begin{tabular}{|c|c|c|c|c|c|c|c|c|c|}
\hline \multirow[b]{2}{*}{ Response term } & \multicolumn{5}{|c|}{ Estimates of model coefficients (standard error) } & \multirow[b]{2}{*}{$\boldsymbol{k}$} & \multirow[b]{2}{*}{$\mathrm{AlCc}$} & \multirow[b]{2}{*}{$\triangle \mathrm{AICc}$} & \multirow[b]{2}{*}{$w$} \\
\hline & Intercept & $\begin{array}{c}\text { Original Habitat - } \\
\text { urban }^{a}\end{array}$ & $\begin{array}{c}\text { Rearing Habitat - } \\
\text { urban }^{a}\end{array}$ & $\begin{array}{l}\text { Completion - } \\
\text { linear }\end{array}$ & $\begin{array}{l}\text { Completion - } \\
\text { quadratic }\end{array}$ & & & & \\
\hline \multirow[t]{3}{*}{ Hatching Success $(n=42)$} & $-0.126(0.422)$ & & & & & 2 & 166.4 & 0.00 & 0.33 \\
\hline & $2.187(3.142)$ & & & $-0.060(0.082)$ & & 3 & 168.2 & 1.80 & 0.13 \\
\hline & $0.146(0.578)$ & $-0.565(0.838)$ & & & & 3 & 168.3 & 1.89 & 0.13 \\
\hline \multirow[t]{3}{*}{ Fledgling Success $(n=30)$} & $4.652(1.876)$ & & $-7.046(3.082)^{\star}$ & & & 3 & 74.3 & 0 & 0.35 \\
\hline & $-9.252(11.493)$ & & $-6.503(2.935)$ & $0.246(0.213)$ & & 4 & 75.3 & 1.07 & 0.20 \\
\hline & $5.112(2.003)$ & $-1.335(1.615)$ & $-6.780(2.828)$ & & & 4 & 76.2 & 1.95 & 0.13 \\
\hline \multirow[t]{4}{*}{ Nestling Weight $(n=68)$} & $11.190(0.180)$ & & $-1.328(0.341)^{*}$ & & & 4 & 178.9 & 0 & 0.27 \\
\hline & $8.822(2.145)$ & & $-1.318(0.330)$ & $0.042(0.038)$ & & 5 & 180.0 & 1.15 & 0.15 \\
\hline & $-32.250(26.282)$ & & $-1.075(0.350)$ & $1.526(0.947)$ & $-0.013(0.009)$ & 6 & 180.1 & 1.22 & 0.15 \\
\hline & $11.300(0.210)$ & $-0.278(0.310)$ & $-1.322(0.335)$ & & & 5 & 180.4 & 1.54 & 0.12 \\
\hline
\end{tabular}

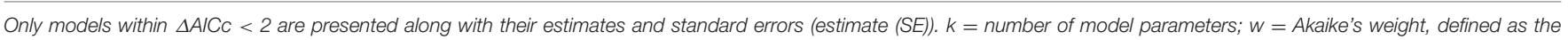

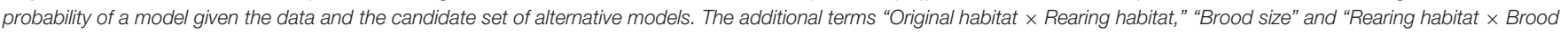

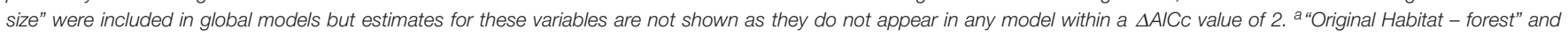

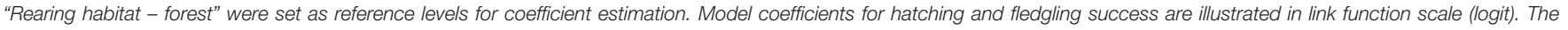

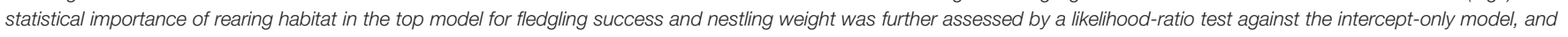
*illustrates $p$-values $<0.05$.

to monitor intestinal parasite load in our study, our results could be explained by potentially higher helminth pressure in our urban location. Aggregation in feeding stations causes high rates of horizontal transmission of directly-transmitted parasites and, hence, affects parasite distribution (Becker et al., 2015). If increased activation of GATA3-induced immunity in our urban birds was, indeed, caused by increased helminth infection, it might thus reflect a parasitological cost imposed by supplementary feeding and contribute to some of the negative effects of supplementary feeding on fitness (Plummer et al., 2013). Results for GATA3 expression (gene ID ENSTGUG00000002134) from an urban great tit study in Sweden were comparable for liver, with higher levels in the city, whereas for blood expression did not differ between sites (Watson et al., 2017).

For the nestling stage, our findings from the cross-fostering experiment provide no evidence that urban as compared to forest origin was associated with higher immune transcript levels in nestlings (Figure 2). Unfortunately, our sparse data from the urban rearing environment do not allow comprehensive conclusions from the full cross-fostering experiment (Figure S2). However, overall, transcript levels of nestling immune genes appeared to be similar across habitats (Figure S2). Thus, 
pending confirmation by a larger dataset, our findings suggest a differential impact of urbanization on the immune system, becoming more pronounced in later life-history stages. The contrasting patterns among age groups might be explained by chronic effects of long-term exposure to urban-specific environmental factors in adults (e.g., Bedrosian et al., 2011). Genetic or prenatal maternal causes for increased TLR4 and GATA3 transcript levels in adult blue tits are made unlikely by our findings that among nestlings reared in the forest, origin (city or forest) did not strongly affect transcript levels of any gene (Figure 2). Hence, the cross-fostering experiment indicates that urban-forest differences in transcript levels of adult blue tits were most likely driven by the environment (Salmón et al., 2016). However, we cannot fully exclude the possibility that genetic or maternal factors are only identifiable in adulthood and not in nestlings. In contrast to our findings, a recent study on great tits did report differences in immune status between urban and rural nestlings (Bailly et al., 2016a). Interestingly, the differences were opposite to those we found for adults blue tits: using physiological assays, rather than gene expression studies, Bailly et al. (2016a) show that urban nestlings produce less haptoglobin (a marker of inflammation) than forest birds, and offer as an explanation that haptoglobin production is compromised by food resource availability in the urban site. Although caution is needed when comparing different species and inflammatory markers, the opposite findings for the age groups might reflect different trade-offs between immunity and development: under resource restriction, growing nestlings might not be able to mount costly responses in the same way as fully grown adults (Sheldon and Verhulst, 1996; Norris and Evans, 2000; Alonso-Alvarez and Tella, 2001).

Our results contribute to a body of evidence suggesting that urban living has reproductive costs and can impact the health of wild animals by altering their immune system (Audet et al., 2016; Bailly et al., 2016a; Watson et al., 2017). We acknowledge that caution is needed when interpreting our result given our sample size and the existence of only one urban-forest study pair and one study year. However, our experimental approach, with within-forest and within-city controls, allows us to draw conclusions on the causal links between immunity, fitness and the urban environment in our study system. Furthermore, the results generally confirm our original predictions and are in line with widespread evidence of reductions in fitness in urban environments (Chamberlain et al., 2009; Bailly et al., 2016b) and with recent discoveries on the effect of the urban environment on gene expression profiles in wild birds (Watson et al., 2017). We find evidence for elevated expression of immune genes in

\section{REFERENCES}

Alberti, M. (2015). Eco-evolutionary dynamics in an urbanizing planet. Trends Ecol. Evol. 30, 114-126. doi: 10.1016/j.tree.2014.11.007

Alonso-Alvarez, C., and Tella, J. L. (2001). Effects of experimental food restriction and body-mass changes on the avian T-cell-mediated immune response. Can. J. Zool. 79, 101-105. doi: 10.1139/z00-190 adults of our urban compared to our forest population, and data from our cross-fostering experiment indicate that such changes are best explained by environmental factors. In combination with our twin study on reduced food availability and modified provisioning in the city (Pollock et al., 2017), we tentatively identify links between resource limitation and altered immunity. To better understand the impact of urbanization on the immune system of wild animals, we need fine-scale characterization of the urban environment including parasite assemblies, coupled with a broader immune assessment of wild populations and information on fitness across life stages. Such information would reveal the role of the immune system for adaptation to urban life, as well as the long-term demographic consequences of altered immunity for urban-dwelling species.

\section{AUTHOR CONTRIBUTIONS}

PC-L, BH, DD, SB, and TB conceived the original study and designed experimental procedures. PC-L, DD, CP, and $\mathrm{BH}$ carried out field work, and PC-L, PO, MM, LW, and FB performed laboratory analysis. Statistical analyses were done by PC-L with advice from DD and BH. PC-L, BH, and DD wrote the manuscript with input from all other co-authors.

\section{FUNDING}

PC-L was funded by a postgraduate scholarship from Iberdrola Foundation. Funding of DD and of gene analysis was provided by a Marie-Curie Career Integration Grant to BH [EC CIG (618578) Wildclocks].

\section{ACKNOWLEDGMENTS}

We would like to thank Dan Haydon, Barbara Mable, and the IBAHCM for their support of the project. We would also like to thank Jessica Clark, Stephen Larcombe, Steve Duncan, Bernard Lundie, Paul Baker, Stewart White, Kim Mortega, Ruedi Nager, Iain Malzer, Paul Jerem, Ana Monteiro, and Yoana Ivanova for their help in the field and in the laboratory. We acknowledge the Trustees of the RSFS Forest Trust for access to Cashel Forest. Two reviewers provided helpful advice that greatly improved an earlier version of the manuscript.

\section{SUPPLEMENTARY MATERIAL}

The Supplementary Material for this article can be found online at: http://journal.frontiersin.org/article/10.3389/fevo. 2017.00064/full\#supplementary-material 
Audet, J. N., Ducatez, S., and Lefebvre, L. (2016). The town bird and the country bird: problem solving and immunocompetence vary with urbanization. Behav. Ecol. 27, 637-644. doi: 10.1093/beheco/arv201

Bailly, J., Scheifler, R., Belvalette, M., Garnier, S., Boissier, E., Anne, V., et al. (2016a). Negative impact of urban habitat on immunity in the great tit Parus major. Oecologia 182, 1053-1062. doi: 10.1007/s00442-016-3730-2

Bailly, J., Scheifler, R., Berthe, S., Clément-Demange, V. A., Leblond, M., Pasteur, B., et al. (2016b). From eggs to fledging: Negative impact of urban habitat on reproduction in two tit species. J. Ornithol. 157, 377-392. doi: $10.1007 / \mathrm{s} 10336-015-1293-3$

Barton, K. (2016). MuMIn: Multi-Model Inference. $R$ package version 1.15.6. Available online at: http://cran.r-project.org/package=MuMIn

Bates, D., Maechler, M., Bolker, B., and Walker, S. (2014). Ime4: Linear MixedEffects Models using Eigen and S4. R Package Version 1.1-7. Available online at: http://cran.r-project.org/package $=$ lme4

Becker, D. J., Streicker, D. G., and Altizer, S. (2015). Linking anthropogenic resources to wildlife-pathogen dynamics: a review and meta-analysis. Ecol. Lett. 18, 483-495. doi: 10.1111/ele.12428

Bedrosian, T. A., Fonken, L. K., Walton, J. C., and Nelson, R. J. (2011). Chronic exposure to dim light at night suppresses immune responses in Siberian hamsters. Biol. Lett. 7, 468-471. doi: 10.1098/rsbl.2010.1108

Blount, J. D., Metcalfe, N. B., Birkhead, T. R., and Surai, P. F. (2003). Carotenoid modulation of immune function and sexual attractiveness in zebra finches. Science 300, 125-127. doi: 10.1126/science.1082142

Bonier, F. (2012). Hormones in the city: Endocrine ecology of urban birds. Horm. Behav. 61, 763-772. doi: 10.1016/j.yhbeh.2012.03.016

Burnham, K. P. (2004). Multimodel inference: understanding AIC and BIC in model selection. Sociol. Methods Res. 33, 261-304. doi: 10.1177/0049124104268644

Burnham, K. P., and Anderson, D. R. (2002). Model Selection and Multimodel Inference, 2nd Edn. New York, NY: Springer-Verlag New York.

Burnham, K. P., Anderson, D. R., and Huyvaert, K. P. (2011). AIC model selection and multimodel inference in behavioral ecology: some background, observations, and comparisons. Behav. Ecol. Sociobiol. 65, 23-35. doi: 10.1007/s00265-010-1029-6

Chamberlain, D. E., Cannon, A. R., Toms, M. P., and Leech, D. I. (2009). Avian productivity in urban landscapes: a review and meta-analysis. Ibis 151, 1-18. doi: 10.1111/j.1474-919X.2008.00899.x

Davies, S., Lane, S., Meddle, S. L., Tsutsui, K., and Deviche, P. (2016). The ecological and physiological bases of variation in the phenology of gonad growth in an urban and desert songbird. Gen. Comp. Endocrinol. 230, 17-25. doi: 10.1016/j.ygcen.2016.03.013

Divanovic, S., Trompette, A., Atabani, S. F., Madan, R., Golenbock, D. T., Visintin, A., et al. (2005). Negative regulation of Toll-like receptor 4 signaling by the Tolllike receptor homolog RP105. Nat. Immunol. 6, 571-578. doi: 10.1038/ni1198

Dominoni, D. M., Greif, S., Nemeth, E., and Brumm, H. (2016). Airport noise predicts song timing of European birds. Ecol. Evol. 6, 6151-6159. doi: $10.1002 /$ ece 3.2357

Dominoni, D. M., Helm, B., Lehmann, M., Dowse, H. B., and Partecke, J. (2013a). Clocks for the city: circadian differences between forest and city songbirds. Proc. R. Soc. B 280:20130593. doi: 10.1098/rspb.2013.0593

Dominoni, D., Quetting, M., and Partecke, J. (2013b). Artificial light at night advances avian reproductive physiology. Proc. R. Soc. B 280:20123017. doi: $10.1098 /$ rspb.2012.3017

Evans, K. L., Gaston, K. J., Sharp, S. P., McGowan, A., Simeoni, M., and Hatchwell, B. J. (2009). Effects of urbanisation on disease prevalence and age structure in blackbird Turdus merula populations. Oikos 118, 774-782. doi: 10.1111/j.1600-0706.2008.17226.x

Fokidis, B. H., Greiner, E. C., and Deviche, P. (2008). Interspecific variation in avian blood parasites and haematology associated with urbanization in a desert habitat. J. Avian Biol. 39, 300-310. doi: 10.1111/j.0908-8857.2008. 04248.x

Fonken, L. K., Weil, Z. M., and Nelson, R. J. (2013). Mice exposed to dim light at night exaggerate inflammatory responses to lipopolysaccharide. Brain. Behav. Immun. 34, 159-163. doi: 10.1016/j.bbi.2013.08.011

Gil, D., Honarmand, M., Pascual, J., Perez-Mena, E., and Macias Garcia, C. (2014). Birds living near airports advance their dawn chorus and reduce overlap with aircraft noise. Behav. Ecol. 26, 435-443. doi: 10.1093/beheco/aru207
Giraudeau, M., Mousel, M., Earl, S., and McGraw, K. (2014). Parasites in the city: degree of urbanization predicts poxvirus and coccidian infections in house finches (Haemorhous mexicanus). PLoS ONE 9:e86747. doi: 10.1371/journal.pone.0086747

Grimm, N. B., Faeth, S. H., Golubiewski, N. E., Redman, C. L., Wu, J., Bai, X., et al. (2008). Global change and the ecology of cities. Science 319, 756-760. doi: $10.1126 /$ science. 1150195

Halliwell, B., and Gutteridge, J. M. (2002). Free Radicals in Biology and Medicine. Oxford: Oxford University Press.

Harrison, X. (2015). A comparison of observation-level random effect and BetaBinomial models for modelling overdispersion in Binomial data in ecology and evolution. PeerJ 3:e1114. doi: 10.7717/peerj.1114

Hellgren, O., Waldenström, J., and Bensch, S. (2004). A new PCR assay for simultaneous studies of Leucocytozoon, Plasmodium, and Haemoproteus from avian blood. J. Parasitol. 90, 797-802. doi: 10.1645/GE-184R1

Isaksson, C. (2010). Pollution and its impact on wild animals: a meta-analysis on oxidative stress. Ecohealth 7, 342-350. doi: 10.1007/s10393-010-0345-7

Isaksson, C. (2015). Urbanization, oxidative stress and inflammation: a question of evolving, acclimatizing or coping with urban environmental stress. Funct. Ecol. 29, 913-923. doi: 10.1111/1365-2435.12477

Lamb, C. T., Mowat, G., Mclellan, B. N., Nielsen, S. E., and Boutin, S. (2017). Forbidden fruit : human settlement and abundant fruit create an ecological trap for an apex omnivore. J. Anim. Ecol. 86, 55-65. doi: 10.1111/1365-2656.12589

Larsson, S. C., Kumlin, M., Ingelman-Sundberg, M., and Wolk, A. (2004). Dietary long-chain n-3 fatty acids for the prevention of cancer: a review of potential mechanisms. Am. J. Clin. Nutr. 79, 935-945.

Lee, C. C., Avalos, A. M., and Ploegh, H. L. (2012). Accessory molecules for Toll-like receptors and their function. Nat. Rev. Immunol. 12, 168-179. doi: 10.1038/nri3151

Liu, Y., Yin, H., Zhao, M. and Lu, Q. (2014). TLR2 and TLR4 in autoimmune diseases: a comprehensive review. Clin. Rev. Allerg. Immunol. 47, 136-147. doi: 10.1007/s12016-013-8402-y

Martin, L. B., Coon, C. A. C., Liebl, A. L., and Schrey, A. W. (2014). Surveillance for microbes and range expansion in house sparrows. Proc. R. Soc. B 281:20132690. doi: 10.1098/rspb.2013.2690

Martin, L. B., Hopkins, W. A., Mydlarz, L. D., and Rohr, J. R. (2010). The effects of anthropogenic global changes on immune functions and disease resistance. Ann. N. Y. Acad. Sci. 1195, 129-148. doi: 10.1111/j.1749-6632.2010.05454.x

McGraw, K. J., Crino, O. L., Medina-Jerez, W., and Nolan, P. M. (2006). Effect of dietary carotenoid supplementation on food intake and immune function in a songbird with no carotenoid coloration. Ethology 112, 1209-1216. doi: 10.1111/j.1439-0310.2006.01280.x

Medzhitov, R. (2001). Toll-like receptors and innate immunity. Nat. Rev. Immunol. 1, 135-145. doi: 10.1038/35100529

Mueller, J. C., Kuhl, H., Timmermann, B., and Kempenaers, B. (2016). Characterization of the genome and transcriptome of the blue tit Cyanistes caeruleus : polymorphisms, sex-biased expression and selection signals. Mol. Ecol. Resour. 16, 549-561. doi: 10.1111/1755-0998.12450

Mueller, J. C., Partecke, J., Hatchwell, B. J., Gaston, K. J., and Evans, K. L. (2013). Candidate gene polymorphisms for behavioural adaptations during urbanization in blackbirds. Mol. Ecol. 22, 3629-3637. doi: 10.1111/mec.12288

Munshi-South, J., and Kharchenko, K. (2010). Rapid, pervasive genetic differentiation of urban white-footed mouse (Peromyscus leucopus) populations in New York City. Mol. Ecol. 19, 4242-4254. doi: 10.1111/j.1365-294X.2010.04816.x

Murray, M., Edwards, M. A., Abercrombie, B., Cassady, C., and Clair, S. (2015). Poor health is associated with use of anthropogenic resources in an urban carnivore. Proc. R. Soc. B 282:20150009. doi: 10.1098/rspb.2015.0009

Neiderud, C.-J. (2015). How urbanization affects the epidemiology of emerging infectious diseases. Infect. Ecol. Epidemiol. 5:27060. doi: 10.3402/iee.v5.27060

Nemeth, E., Pieretti, N., Zollinger, S. A., Geberzahn, N., Partecke, J., Miranda, A. C., et al. (2013). Bird song and anthropogenic noise: vocal constraints may explain why birds sing higher-frequency songs in cities. Proc. R. Soc. B 280:20122798. doi: 10.1098/rspb.2012.2798

Nettle, D., Andrews, C., Reichert, S., Bedford, T., Kolenda, C., Parker, C., et al. (2017). Early-life adversity accelerates cellular ageing and affects adult inflammation: experimental evidence from the European starling. Sci. Rep. 7:40794. doi: 10.1038/srep40794 
Norris, K., and Evans, M. R. (2000). Ecological immunology: life history trade-offs and immune defense in birds. Behav. Ecol. 11, 19-26. doi: 10.1093/beheco/11.1.19

O'Shaughnessy, P. J., Marsh, P., and Dudley, K. (1994). Follicle-stimulating hormone receptor mRNA in the mouse ovary during post-natal development in the normal mouse and in the adult hypogonadal (hpg) mouse: structure of alternate transcripts. Mol. Cell. Endocrinol. 101, 197-201. doi: 10.1016/0303-7207(94)90235-6

O'Shaughnessy, P. J., Morris, I. D., and Baker, P. J. (2008). Leydig cell regeneration and expression of cell signaling molecules in the germ cell-free testis. Reproduction 135, 851-858. doi: 10.1530/REP-07-0529

O'Shaughnessy, P. J., and Murphy, L. (1993). Cytochrome P-450 17 -hydroxylase protein and mRNA in the testis of the testicular feminized (Tfm) mouse. J. Mol. Endocrinol. 11, 77-82. doi: 10.1677/jme.0.0110077

Olias, P., Adam, I., Meyer, A., Scharff, C., and Gruber, A. D. (2014). Reference genes for quantitative gene expression studies in multiple avian species. PLoS ONE 9:e99678. doi: 10.1371/journal.pone.0099678

Partecke, J., Schwabl, I., and Gwinner, E. (2006). Stress and the city: urbanization and its effects on the stress physiology in European blackbirds. Ecology 87, 1945-1952. doi: 10.1890/0012-9658(2006)87[1945:SATCUA]2.0.CO;2

Plummer, K. E., Bearhop, S., Leech, D. I., Chamberlain, D. E., and Blount, J. D. (2013). Winter food provisioning reduces future breeding performance in a wild bird. Sci. Rep. 3:2002. doi: 10.1038/srep02002

Pollock, C. J., Capilla-Lasheras, P., McGill, R. A. R., Helm, B., and Dominoni, D. (2017). Integrated behavioural and stable isotope data reveal altered diet linked to low breeding success in urban-dwelling blue tits (Cyanistes caeruleus). Sci. Rep.

R Core Team (2016). R: A Language and Environment for Statistical Computing. $R$ Foundation for Statistical Computing. Vienna. Available online at: http://www.r-project.org/

Salmón, P., Nilsson, J. F., Nord, A., Bensch, S., and Isaksson, C. (2016). Urban environment shortens telomere length in nestling great tits, Parus major. Biol. Lett. 12:20160155. doi: 10.1098/rsbl.2016.0155

Schoech, S. J., Bowman, R., and Reynolds, S. J. (2004). Food supplementation and possible mechanisms underlying early breeding in the Florida Scrub-Jay (Aphelocoma coerulescens). Horm. Behav. 46, 565-573. doi: 10.1016/j.yhbeh.2004.06.005

Seto, K. C., Güneralp, B., and Hutyra, L. R. (2012). Global forecasts of urban expansion to 2030 and direct impacts on biodiversity and carbon pools. Proc. Natl. Acad. Sci. U.S.A. 109, 16083-16088. doi: 10.1073/pnas.1211 658109
Sheldon, B. C., and Verhulst, S. (1996). Ecological immunology: costly parasite defences and trade-offs in evolutionary ecology. Trends Ecol. Evol. 11, 317-321. doi: 10.1016/0169-5347(96)10039-2

Sprau, P., Mouchet, A., and Dingemanse, N. J. (2017). Multidimensional environmental predictors of variation in avian forest and city life histories. Behav. Ecol. 28, 59-68. doi: 10.1093/beheco/arw130

Sumasgutner, P., Nemeth, E., Tebb, G., Krenn, H. W., and Gamauf, A. (2014). Hard times in the city - attractive nest sites but insufficient food supply lead to low reproduction rates in a bird of prey. Front. Zool. 11:48. doi: 10.1186/1742-9994-11-48

Tindemans, I., Serafini, N., DiSanto, J. P., and Hendriks, R. W. (2014). GATA-3 function in innate and adaptive immunity. Immunity 41, 191-206. doi: 10.1016/j.immuni.2014.06.006

Toledo, A., Andersson, M. N., Wang, H.-L., Salmón, P., Watson, H., Burdge, G. C., et al. (2016). Fatty acid profiles of great tit (Parus major) eggs differ between urban and rural habitats, but not between coniferous and deciduous forests. Sci. Nat. 103:55. doi: 10.1007/s00114-016-1381-0

Videvall, E., Cornwallis, C. K., Palinauskas, V., Valkiūnas, G., and Hellgren, O. (2015). The avian transcriptome response to malaria infection. Mol. Biol. Evol. 32, 1255-1267. doi: 10.1093/molbev/msv016

Wang, Y., Su, M. A., and Wan, Y. Y. (2011). an essential role of the transcription factor GATA-3 for the function of regulatory T cells. Immunity 35, 337-348. doi: 10.1016/j.immuni.2011.08.012

Warren, W. C., Clayton, D. F., Ellegren, H., Arnold, A. P., Hillier, L. W., Künstner, A., et al. (2010). The genome of a songbird. Nature 464, 757-762. doi: $10.1038 /$ nature08819

Watson, H., Videvall, E., Andersson, M. N., and Isaksson, C. (2017). Transcriptome analysis of a wild bird reveals physiological responses to the urban environment. Sci. Rep. 7:44180. doi: 10.1038/srep44180

Conflict of Interest Statement: The authors declare that the research was conducted in the absence of any commercial or financial relationships that could be construed as a potential conflict of interest.

Copyright (C) 2017 Capilla-Lasheras, Dominoni, Babayan, O’Shaughnessy, Mladenova, Woodford, Pollock, Barr, Baldini and Helm. This is an open-access article distributed under the terms of the Creative Commons Attribution License (CC $B Y)$. The use, distribution or reproduction in other forums is permitted, provided the original author(s) or licensor are credited and that the original publication in this journal is cited, in accordance with accepted academic practice. No use, distribution or reproduction is permitted which does not comply with these terms. 